\title{
The wrong end of the scope
}

can usually find the time to fit in an extra colonoscopy without too much difficulty-unless it is my own-but I eventually did it! Granted, I got around to it a few (actually 4) years later than was recommended after my last examination 9 years ago. I don't mind divulging confidential medical information to tell you that a diminutive tubular adenoma was discovered during my first colonoscopy 12 years ago and that I had a negative result after a follow-up procedure 3 years later.

Like many physicians I am a reluctant patient (Dudley, S. JAMA 302, 609-610; 2009), but I try to comply with what I understand to be the most relevant health standards. In conjunction with my colonoscopy I had my first complete physical examination in probably 20 years that was outside of 'insurance physicals' (weight, BMI, blood pressure, electrocardiography, complete blood count, cholesterol levels, liver and kidney function panel and urinalysis, including drug testing). When I told my doctor that "I exercise to eat and drink" (as many readers know, I am a big fan of various forms of physical exercise: jogging, core exercises and biking), he told me he was concerned about what would happen when I couldn't exercise anymore-God forbid! I am a bit overweight and my BMI has increased somewhat owing to my shrinking stature, which is another challenge of middle age. Even though I have maintained my weight, this decline in height inevitably causes an increase in BMI (for me from $25.4 \mathrm{~kg} / \mathrm{m}^{2}$ to $26.1 \mathrm{~kg} / \mathrm{m}^{2}$ ). How unfair! I am also challenged by a borderline elevation in blood pressure that is different in both arms. Is a diastolic pressure of $130 \mathrm{mmHg}$ really worth treating in an otherwise healthy, athletic individual who has no other cardiac risk factors? And what about treating someone with a total cholesterol level of $200 \mathrm{mg} / \mathrm{dl}(5.18 \mathrm{mmol} / \mathrm{l})$ and an HDL level of $60 \mathrm{mg} / \mathrm{dl}(1.56 \mathrm{mmol} / \mathrm{l})$ ? Thank goodness for the red wine.

So, back to the colonoscopy. I dare not complain about the preparation-it really wasn't too bad. I've proscribed phosphate preparations for the majority of my patients and I found the polyethylene glycol (PEG) mixed with a 'sports drink' quite tolerable. However, I had a busy clinic day before the procedure, which meant that our GI specialty nurses were somewhat amused by my guzzling a bottle of citrate of magnesia during a mid-day lecture to them. Clinic continued with no issues, that is until a 'surge' about $2.5 \mathrm{~h}$ later. When I finished clinic and arrived home that night, my wife had decided to forgo cooking our usual gourmet meal for a movie while I demolished $64 \mathrm{oz}(\sim 1.91)$ of PEG solution in about $90 \mathrm{~min}$. I was surprised to find that, although I appeared pregnant and was spewing forth trumpeting noises worthy of a brass band, not much happened until about 3 am. My prostate and bowel preparation were in synch for the remainder of the Erev (eve of) scoping and by morning, happily, I was clear.

The most surreal aspect of the colonoscopy experience for me, of course, was being on the other (wrong) side of the cart. Exposing oneself to familiar staff (albeit from the patient's perspective) does engender sympathy, particularly when the exposed surface is the 'butt' of their humor. Despite the early hour-chosen in an attempt to avoid 'exposure' during peak hours and to allow me to have a full productive day-the gurney ride through the endoscopy unit in the presence of other patients, passing staff and colleagues, was as humbling an experience as it gets.

I agree with most of my patients that the procedure itself is the least of one's troubles (for me, it was the least embarrassing aspect as I schmoozed with my colleague who performed the procedure). Happily, my right colon was clear of flat lesions and the withdrawal time was only $6 \mathrm{~min}$. A couple of hyperplastic polyps were found but the overall examination results were reassuring, and so I'm back to the 5-10-year schedule-however that pans out in practice. In his article "A Paucity of Physicians", Steve Dudley notes that physician patients are notoriously prone to forgo the regular check-ups we promote so earnestly for others.

As frequently happens with the lay public, it is often the physician's spouse (as it was in my case) who encourages a medical encounter. It is an occupational hazard for physicians to minimize their own clinical status (vide supra), perhaps because we know the implications of our own symptoms so thoroughly. However, we have just as much difficulty as any other person in putting lifestyle changes into practice. So, in relation to the dietary advice I received to "eat a healthy breakfast," I've put forth a challenge to our dietician to find me direct evidence of the health benefits of eating a breakfast that consists of more than my morning cup of coffee. Who has time?

doi:10.1038/nrgastro.2009.164
4 The most

surreal aspect ... was being on the other (wrong) side of the cart 77

Stephen B. Hanauer is the Editor-in-Chief of Nature Reviews Gastroenterology \& Hepatology.

Competing interests

S. B. Hanauer declares no competing interests. 